\title{
A COMPARATIVE STUDY BETWEEN ROPIVACAINE AND BUPIVACAINE ALONG WITH FENTANYL AS AN ADJUVANT TO BOTH TO OBSERVE THE EFFICACY OF POSTOPERATIVE EPIDURAL ANALGESIA
}

\author{
Joydeep Debnath', Anupam Chakrabarti², Vaskar Majumdar ${ }^{3}$ \\ ${ }^{1}$ Senior Resident, Department of Anaesthesiology, AGMC, Agartala. \\ ${ }^{2}$ Assistant Professor, Department of Anaesthesiology, AGMC, Agartala. \\ ${ }^{3}$ Assistant Professor, Department of Anaesthesiology, AGMC, Agartala.
}

\begin{abstract}
BACKGROUND

Epidural analgesia is considered by many as 'gold standard' of analgesic technique for postoperative analgesia after lower limb as well as abdominal surgeries. Epidural analgesia has the ability to maintain continuous analgesia after placement of an epidural catheter with the analgesic drug thus making it suitable for continuous postoperative pain relief and early ambulation.

Epidural opiates in combination with local anaesthetics are commonly used for postoperative analgesia with several lines of evidence indicate that opiates administered through the epidural route are safe with proven benefits such as good pain relief, less pain during movement, better mental status, fewer complication. Even though bupivacaine, the ideal local anaesthetic and has similar pharmacological profile with ropivacaine, but which cardiac safety margin is lower than ropivacaine due to its Senantiomer.
\end{abstract}

\section{METHOD}

After approval from ethical committee, 160 no of consenting patients of ASA 1 and 2 were studied in two groups (80 patients each); Group A-received $0.125 \%$ bupivacaine $8 \mathrm{~mL}$ with fentanyl $25 \mu \mathrm{g}$; Group B-received $0.2 \%$ ropivacaine $8 \mathrm{~mL}$ with fentanyl 25 $\mu \mathrm{g}$ through epidural route. Onset of analgesia, duration, quality of analgesia studied after injecting drug up to 6 hrs. postoperative. Statistical Analysis: Data entered by SPSS 21 Version and analysis through independent $\mathrm{t}$ test and chi-square test. P value of $<0.05$ was considered as significant.

\section{RESULTS}

Duration of analgesia of bupivacaine-fentanyl study group was approx. $2 \mathrm{hrs}$. and 15 mins. and in ropivacaine-fentanyl group was $1 \mathrm{hrs}$. and $45 \mathrm{~min}$. Bupivacaine-fentanyl study group had a faster onset time with $12 \mathrm{~min}$ approx. while in ropivacaine-fentanyl group it was around $15 \mathrm{~min}$. fall in blood pressure and heart rate were not drastic in both the groups. Pain relief score was more with bupivacaine in comparison to ropivacaine for postoperative analgesia.

\section{CONCLUSION}

Bupivacaine-fentanyl study group had a faster onset time, longer duration in compared to ropivacaine. Fall in blood pressure and heart rate were not drastic in both the groups. Pain relief which was measured with pain relief score was more with bupivacaine in comparison to ropivacaine for postoperative analgesia.

\section{KEYWORDS}

Postoperative Epidural Analgesia, Bupivacaine, Ropivacaine, Fentanyl, Lower Limb Surgery.

HOW TO CITE THIS ARTICLE: Debnath J, Chakrabarti A, Majumdar V. A comparative study between ropivacaine and bupivacaine along with fentanyl as an adjuvant to both to observe the efficacy of postoperative epidural analgesia. J. Evolution Med. Dent. Sci. 2016;5(70):5076-5080, DOI: 10.14260/jemds/2016/1153

\section{INTRODUCTION}

"Pain is an unpleasant sensory and emotional experience associated with actual or potential tissue damage or described in terms of such damage."

The International Association for the Study of Pain (IASP). This classification further states that pain is always subjective and that it is a sensation in part of the body. At the same time, it is unpleasant and therefore also has an emotional component.

Financial or Other, Competing Interest: None.

Submission 03-07-2016, Peer Review 27-07-2016,

Acceptance 02-08-2016, Published 01-09-2016.

Corresponding Author:

Dr. Joydeep Debnath,

Dhaleswar, Road No.9,

P. O. Dhaleswar,

Agartala-799007,

Tripura $(W)$.

E-mail: jdebnath797@gmail.com

DOI: $10.14260 /$ jemds $/ 2016 / 1153$
Though different modalities of pain management technique are available like intravenous, epidural, spinal, combined spinal, epidural, but analgesic medication through epidural route is an advance and excellent route of providing patient relief from pain after major surgeries of abdominal and lower limb surgeries. An epidural analgesia is considered by many as 'gold standard' of analgesic technique for postoperative analgesia after lower limb as well as abdominal surgeries. It provides dynamic analgesia allowing the patient to resume normal activities unlimited by pain. Epidural analgesia has the ability to maintain continuous analgesia after placement of an epidural catheter with the analgesic drug thus making it suitable for continuous postoperative pain relief and early ambulation.[1-3]

For major orthopaedic surgery such as total hip and knee arthroplasty regional anaesthesia is believed to have certain advantages over general anaesthesia.[3-5]

The two most common regional techniques are spinal and epidural anaesthesia. Spinal block is a simple method, which 
requires a small dose of local anaesthetic to establish an intense and reliable block quickly. Epidural block with a catheter technique is technically somewhat more difficult, but offers the possibilities of extending the block during surgery and of pain relief with a local anaesthetic and/or opioids in the postoperative period. However, both techniques have drawbacks. To avoid some of the problems of epidural and spinal blocks, a Combined Spinal Epidural (CSE) technique has been described.4,5

Apart from the providing pain relief, it also helps in attenuation of stress response. An ideal local anaesthetic will provide quick onset, sufficient sensory blockade along with maintaining haemodynamic stability with minimal systemic side effects. Several drugs like mepivacaine, tetracaine and chloroprocaine have been used before and most of these drug produced unwanted side effects that led to discontinuation of use of these drugs. Among the drugs used lignocaine, bupivacaine, levobupivacaine, and ropivacaine are in current use. 6

Intravenous opiates use is limited because of side effects such as respiratory depression. Now a days, epidural opiates in combination with local anaesthetics are commonly used for postoperative analgesia. Several lines of evidence indicate that opiates administered through the epidural route are safe with proven benefits such as good pain relief, less pain during movement, better mental status, fewer cardiopulmonary complications, less thromboembolism, and earlier discharge from the hospital. ${ }^{6}$

Even though, bupivacaine, the ideal local anaesthetic is popularly used in epidural space for analgesia, the fear of inadvertent injection of the drug intravascularly and resulting in cardiac arrest, which is difficult to resuscitate made us look at other drugs. Ropivacaine, the recently introduced longacting amide local anaesthetic derived from bupivacaine is claimed to have lesser cardiovascular side effects due to it being a S-enantiomer.7,8 It is said to be better in its cardiovascular profile as patient can be revived from cardiovascular side effects much faster and with better outcome then when it occurs with bupivacaine. Inquest for searching the ideal drug for epidural space, ropivacaine, an enantiomer of bupivacaine was introduced recently. It is said to have similar pharmacological profile as that of bupivacaine, but with much better safety margin. Pharmacodynamic studies have found that ropivacaine blocks C fibers faster than A fibers and produces a frequencydependent block. Blockade of A fibers was less with ropivacaine than with similar concentrations of bupivacaine whereas the degree of $\mathrm{C}$-fibre block was similar with both drugs. ${ }^{6,7)}$ This differential blocking effect of ropivacaine provides analgesia with less motor block than comparable concentrations of bupivacaine. 9,10

Studies are being conducted comparing different concentrations of bupivacaine in different routes of administration with that of ropivacaine. It has been demonstrated that co-administering epidural fentanyl and bupivacaine improves the quality of analgesia and reduces the required drug dosage in comparison with bupivacaine alone.

Ropivacaine is a long-acting local amide anaesthetic, which is structurally very similar to bupivacaine, but produces less motor block and less cardiac and central nervous system toxicity. It is also about $40 \%$ less potent than bupivacaine. ${ }^{6}$ So, following study was taken up to compare the analgesic effect, duration of action, and haemodynamic changes of $0.125 \%$ bupivacaine with that of $0.25 \%$ ropivacaine along with fentanyl $25 \mathrm{ug}$, which is an equipotent dose in elective lower limb surgeries for postoperative analgesia.

\section{AIMS}

The aim of the present study is to compare between $0.2 \%$ ropivacaine along with fentanyl $25 \mu \mathrm{g}$ and $0.125 \%$ bupivacaine along with fentanyl $25 \mu \mathrm{g}$ with regards to its duration of postoperative analgesia, quality of analgesia, and haemodynamics in patients undergoing elective lower limb surgeries under spinal anaesthesia.

\section{OBJECTIVES}

- To know and compare the duration of postoperative analgesia.

- To compare the quality of postoperative analgesia in patients between ropivacaine and bupivacaine in patients undergoing lower limb surgeries under spinal anaesthesia.

- Haemodynamic differences in postoperative patients.

\section{MATERIALS AND METHOD}

After obtaining ethical committee clearance, a Randomised Control Trial single blind study studied from January 2014 to June 2015 at AGMC, GB Pant Hospital, Department of Anaesthesiology, operation theatre. Informed consent taken from each patient. 160 no. of ASA grade 1, 2 randomly divided into two groups of 80 each by WINPEPI software where $\mathrm{Z} \alpha=1.96, \mathrm{Z} \beta=0.84$, GROUP A-(received $0.125 \%$ bupivacaine 8 $\mathrm{mL}$ with fentanyl $25 \mu \mathrm{g}$ ) and GROUP B-(received $0.2 \%$ ropivacaine $8 \mathrm{~mL}$ with fentanyl $25 \mu \mathrm{g}$ ) and they were posted for lower limb surgeries. In OT after placement of epidural catheter at $\mathrm{L}_{2}-\mathrm{L}_{3}$ and leaving the catheter in situ $5 \mathrm{~cm}$ in epidural space, spinal anaesthesia done at $\mathrm{L}_{3}-\mathrm{L}_{4} 0.3 \mathrm{mg} / \mathrm{kg}$ $0.5 \%$ bupivacaine heavy. In postoperative ward epidural analgesia, $1^{\text {st }}$ dose given when the patient felt pain that is when VAS more than 5.

\section{Exclusion criteria}

Patients belonging to ASA ( 3 and 4 ) and age $(<18,>65$ years), with history of bleeding diathesis, on anticoagulant therapy, history of drug abuse, having history of hypersensitivity to anaesthetic agents, fever, neuromuscular diseases, or spine surgeries and who refuses the procedures were excluded from study.

\section{Statistical Analysis}

Results expressed as the mean and standard deviation or number and percentage. The comparison of normally distributed continuous variable between the group performed by independent $t$ test, categorical data between study group compared by chi-square test; $\mathrm{p}<0.05$ considered as label of significance.

Parameters to be studied: The parameters, which was into consideration for study are;

\section{A. Primary outcome variable}

- Onset of analgesia: Time to reach visual analogue scale $<5$ after the first dose of study drug in the postoperative period. 
- Duration of analgesia: Calculated by time interval from the time to achieve VAS $<5$ to time to reach VAS $\geq 5$ after the first dose of study drug in the postoperative period.

B. Secondary outcome variable: Quality of Analgesia by Pain Relief Scale

- And duration of analgesia, quality of analgesia will be measured postoperatively by visual analogue scale at every $2 \mathrm{~min}$. up to $10 \mathrm{~min}$., then every $5 \mathrm{~min}$. up to $30 \mathrm{~min}$., then every $15 \mathrm{~min}$. up to one hour, then every $1 \mathrm{hrs}$. up to $6 \mathrm{hrs}$.

\section{Visual Analogue Pain Scale}

To determine pain intensity in patients after giving the test drug, patient is asked to point out the scores on the scale.

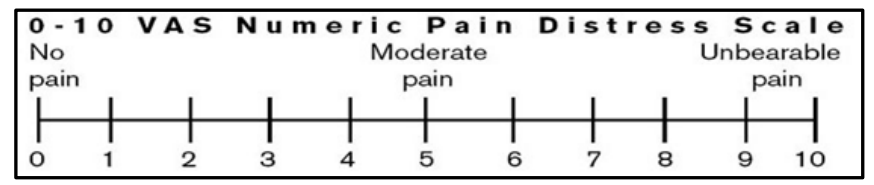

RESULT AND ANALYSIS

Statistical Analysis

\begin{tabular}{|c|c|c|c|}
\hline \multicolumn{4}{|c|}{ Demographic Parameters of all Groups } \\
\hline & $\begin{array}{c}\text { Group A } \\
\text { (n=80) } \\
\text { Mean } \pm \text { S.D. }\end{array}$ & $\begin{array}{c}\text { Group B } \\
\text { (n=80) } \\
\text { Mean } \pm \text { S.D. }\end{array}$ & p Value \\
\hline $\begin{array}{c}\text { Age } \\
\text { (years) }\end{array}$ & $45 \pm 11.55$ & $44.37 \pm 12.16$ & 0.739 \\
\hline $\begin{array}{c}\text { Weight } \\
(\mathrm{kg})\end{array}$ & $57.75 \pm 8.55$ & $58.96 \pm 8.41$ & 0.3682 \\
\hline $\begin{array}{c}\text { Height } \\
(\mathrm{cms})\end{array}$ & $157.45 \pm 7.87$ & $158.61 \pm 8.19$ & 0.362 \\
\hline $\begin{array}{c}\mathrm{BMI} \\
\left(\mathrm{kg} / \mathrm{m}^{2}\right)\end{array}$ & $24.42 \pm 2.15$ & $23.75 \pm 2.52$ & 0.116 \\
\hline \multicolumn{4}{|c|}{ Table 1: Demographic Parameters of the Patients } \\
\hline
\end{tabular}

A total of 160 patients were enrolled into study.

\section{Age}

The age of the patients ranged from 18 to $65 \mathrm{yrs}$. The twotailed $P$ value equals 0.739 . By conventional criteria, this difference is considered to be not statistically significant.

\section{Weight}

The two-tailed $\mathrm{P}$ value equals 0.368 . By conventional criteria, this difference is considered to be not statistically significant.

\section{Height}

The two-tailed $P$ value equals 0.3624 . By conventional criteria, this difference is considered to be not statistically significant.

\begin{tabular}{|c|c|c|}
\hline \multicolumn{3}{|c|}{ Onset of Analgesia } \\
\hline Time to Achieve Visual Analogue Score $<\mathbf{5}$ ( minutes) \\
\hline $\begin{array}{c}\text { GROUP-A } \\
(\text { Mean } \pm \text { S.D.) }\end{array}$ & $\begin{array}{c}\text { GROUP-B } \\
\text { (Mean } \pm \text { S.D.) }\end{array}$ & $\begin{array}{c}\text { p VALUE } \\
(\text { Student ' } t \text { ' test) }\end{array}$ \\
\hline $12 \pm 1.74$ & $14.62 \pm 2.13$ & $<0.001$ \\
\hline \multicolumn{3}{|c|}{ Table2: (Onset of Analgesia) } \\
\hline
\end{tabular}

Group-A: Patients took $12 \pm 1.74$ minutes to regain Visual Analogue score $<5$ and group-B patients took $14.62 \pm 2.13$ minutes. Unpaired student's ' $\mathrm{t}$ ' test was done and $\mathrm{p}$ value was $<0.001$, which is considered to highly statistically significant.

Group-B: Patients took significantly longer time than groupA patients to regain Visual Analogue score $<5$. This concludes that onset of action of analgesia in bupivacaine along with fentanyl group is faster than ropivacaine along with fentanyl group.

\section{CHART 1: DURATION OF POST OPERATIVE} ANALGESIA (hours)

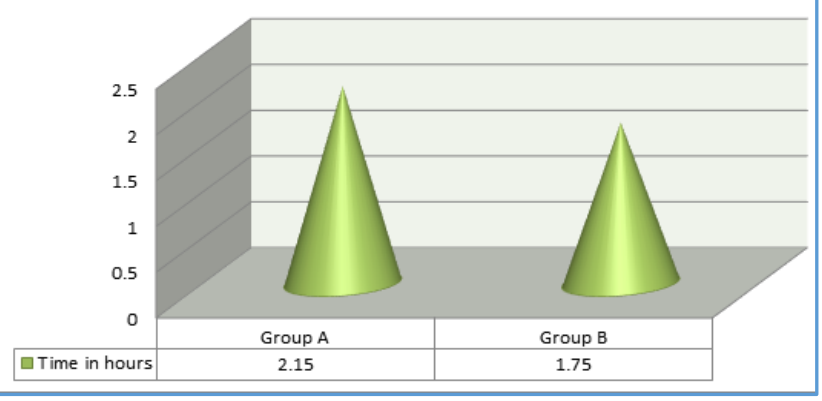

\begin{tabular}{|c|c|c|c|}
\hline \multicolumn{2}{|c|}{ Quality of Analgesia by Pain Relief Scale } & \\
\hline & Group-A & Group-B & $\begin{array}{c}\text { p- } \\
\text { Value }\end{array}$ \\
\hline Not effective at al & 03 & 04 & 1.0 \\
\hline Mildly effective & 27 & 39 & 0.877 \\
\hline Very effective & 40 & 28 & 0.962 \\
\hline $\begin{array}{c}\text { Completely } \\
\text { effective }\end{array}$ & 10 & 09 & 0.828 \\
\hline \multicolumn{4}{|c|}{ Table 3: (Quality of Analgesia) } \\
\hline
\end{tabular}

Though quality of analgesia is insignificant among the individual in both the groups, but it was noticed that analgesia was very effective in $50 \%$ patients of group A compared to group B, which is $35 \%$. Analgesia was mildly effective in $34 \%$ patients of group A compared to group B, which is $48 \%$.

\begin{tabular}{|c|c|c|}
\hline & Group A & Group B \\
\hline Nausea & 5 & 1 \\
Vomiting & 3 & 0 \\
Pruritus & 2 & 0 \\
Hypotension & 4 & 1 \\
\hline Bradycardia & 2 & 0 \\
\hline Respiratory depression & 0 & 0 \\
\hline \multicolumn{2}{|c|}{ Table 4: (Adverse Effects) } \\
\hline
\end{tabular}

\section{DISCUSSION}

Epidural anaesthesia is a central neuraxial block technique with many applications. In 1945, Tuohy introduced the needle, which is still most commonly used for epidural anaesthesia. Improvements in equipment, drugs and technique have made it a very popular and versatile anaesthetic technique as well as an analgesic adjuvant to general anaesthesia and for postoperative analgesia involving the lower limbs, perineum, pelvis, abdomen, and thorax. Both single injection and catheter techniques can be used. 
We conducted a comparative study on 160 patients comparing haemodynamic changes, onset, and duration of analgesia in these patients and randomly dividing them into two groups of 80 each. In Group A, we administered $8 \mathrm{~mL}$ of $0.125 \%$ bupivacaine with fentanyl $25 \mu \mathrm{g}$ and in Group B we administered $8 \mathrm{~mL} 0.2 \%$ ropivacaine with fentanyl $25 \mu \mathrm{g}$.

Bupivacaine is a longer acting amide group, which has been used as a prime agent in epidural anaesthesia and also to provide postoperative pain relief. Ropivacaine is a newer amide longer acting used nowadays as a prime agent due to its fewer side effects and better haemodynamic stability.

Bupivacaine was and still is an ideal drug for epidural analgesia. We found in our study that mean duration of analgesia of bupivacaine and fentanyl group was $2 \mathrm{hrs}$. and 15 min. approx. while in ropivacaine and fentanyl group mean duration was $1 \mathrm{hrs}$. and $45 \mathrm{~min}$. approx. Such similar study was done by Pouzeratte et al where it was stated that bupivacaine when used in combination with an opioid analgesic was more effective than ropivacaine.[11,12,13]

The demand for bupivacaine was less and even the volumes of drugs given for subsequent doses were less as was also stated by the study conducted by Peduto et al.14

When we compared the onset time of analgesia and duration of analgesia, onset of analgesia with bupivacaine group was $12 \mathrm{~min}$. and in ropivacaine group was approx. 15 min., so in bupivacaine group onset was faster, but in both groups, the onset was similar, but the duration of analgesia was more with bupivacaine-fentanyl group than ropivacainefentanyl group in a study conducted by Brown DL et al. ${ }^{15}$

Bupivacaine, because of its structure is said to be more cardiotoxic. K. Knudsen et al observe there was a little fall in both the systolic as diastolic blood pressure with bupivacaine. But, we in our study, haemodynamic stability was checked in this study and noted that some patients of bupivacaine group had a fall in blood pressure over a period of 15 to 30 minutes, but did not notice any drastic fall in blood pressure in first $6 \mathrm{hrs}$. of postoperative first dose of epidural analgesics. ${ }^{16}$

In a previous study by J.B. Dahl et al where they stated that vasoconstrictive property of ropivacaine influences the duration of action in the epidural space, but we found that the duration of analgesia in bupivacaine-fentanyl group was longer than ropivacaine-fentanyl group.

Haemodynamic stability was more in ropivacainefentanyl group as there was a very small fall in mean blood pressure and heart rate, which was stated by Brockway MS et $\mathrm{al}^{17}$ by using the same concentration of bupivacaine and ropivacaine. Ropivacaine produced a slower onset, shorter duration, and less intense motor block. We also came to the same conclusion that bupivacaine at $0.125 \%$ was superior to ropivacaine $0.2 \%$ to maintain the postoperative epidural analgesia.

Grey C. Meister et al ${ }^{7}$ concluded in their study that $0.125 \%$ ropivacaine with fentanyl $2 \mu \mathrm{g} / \mathrm{mL}$ produced equivalent analgesia with significantly less motor block than $0.125 \%$ bupivacaine with fentanyl $2 \mu \mathrm{g} / \mathrm{mL}$ and found that epidural fentanyl reduces anaesthetic requirement by $19-31 \%$ and in corporate with other study found that ropivacaine is $40-50 \%$ less potent than bupivacaine. We have used the equipotent concentration in our study as ropivacaine $0.2 \%$ and bupivacaine $0.125 \%$, but still we found that $0.2 \%$ ropivacaine along with $25 \mu \mathrm{g}$ fentanyl duration is shorter than bupivacaine $0.125 \%$ with $25 \mu$ g fentanyl.

Blocking the afferent neural stimulus by epidural technique is very effective in reducing the classical hormonal and metabolic stress response to surgery especially with the use of continuous analgesia with extradural local anaesthetics. Postoperative epidural analgesia is therefore combined with other forms of postoperative treatment, early forced mobilisation, and early oral nutrition to optimise postoperative recovery has been stated in the study by Gerhard Brodner et al.

Though the duration of single dose analgesia, subjective pain relief score in $0.125 \%$ bupivacaine-fentanyl group is more than $0.2 \%$ ropivacaine-fentanyl group and few side effects like hypotension, bradycardia, nausea, and vomiting in bupivacaine-fentanyl group in comparison to ropivacainefentanyl group with no significant side effects, which have been cited in study by Kanai $\mathrm{A}$ et al that though the motor block and duration of analgesia is more with $0.125 \%$ bupivacaine, still $0.2 \%$ would be better choice for epidural analgesia due to less systemic side effects.

The concentration bupivacaine and ropivacaine used in this study does not cause motor blockade. As stated by Liu SS et $\mathrm{al}^{16}$ lesser concentration will provide comparable analgesia with less motor blockade.

Onset of action is rapid in both group whereas duration is little longer in bupivacaine group. Although, no respiratory depression noted in each group. This results matched with study conducted by Peter S. Hodgson et al where they found both epidural ropivacaine and bupivacaine are improved by the addition of small doses of fentanyl for postoperative analgesia and due to relatively rapid onset, modest duration, and minimal risk of delayed respiratory depression is better suited to PCEA.

Chi-square test was done to compare the haemodynamic stability of both the drugs. We noticed haemodynamic changes in both the group are not significant. In both the group, mild changes in heart rate, blood pressure, and oxygen saturation, which is not all significant up to $6 \mathrm{hrs}$. of the first dose of epidural analgesia.

We came to a conclusion that bupivacaine-fentanyl group that received bupivacaine were much comfortable and happy with the quality of analgesia compared to the Group A where the patients received ropivacaine.

In this study of 80 patients of bupivacaine-fentanyl, few patients have nausea, vomiting, hypotension, bradycardia, pruritus, but in ropivacaine-fentanyl, only pruritus noticed in few patients, which maybe a complication of fentanyl, but comparatively lesser than bupivacaine-fentanyl group.

\section{CONCLUSION}

From this comparative study between $0.2 \%$ ropivacaine and $0.125 \%$ bupivacaine along with fentanyl $125 \mu \mathrm{g}$ as an adjuvant in each group to observe the efficacy of postoperative epidural analgesia in patients undergoing elective lower limb surgeries under spinal anaesthesia on the basis of statistical analysis that among the two local anaesthetic drugs it maybe concluded that,

a. Duration of analgesia was longer and better with bupivacaine.

b. Bupivacaine had a faster onset time. 
c. Haemodynamic cardiovascular stability and other complications were more with bupivacaine compared to ropivacaine though the fall in blood pressure and heart rate were not drastic in both the groups.

d. Quality of analgesia was better with bupivacaine in comparison to ropivacaine.

\section{REFERENCES}

1. Coates MB. Combined subarachnoid and epidural techniques. Anaesthesia 1982;37(1):89-90.

2. Rawal N. Single segment combined subarachnoid and epidural block for caesarean section. Can Anaesth Soc J 1986;33(2):254-5.

3. Modig J, Hjelmstedt A, Sahlstedt B, et al. Comparative influences of epidural and general anaesthesia on deep venous thrombosis and pulmonary embolism after total hip replacement. Acta Chir Scand 1981;147(2):125-30.

4. Rosberg B, Fredin H, Gustafson C. Anaesthetic techniques and surgical blood loss in total hip arthroplasty. Acta Anaesthesiol Scand 1982;26(3):189-93.

5. Johnson A, Bengtsson M, Merits $\mathrm{H}$, et al. Anaesthesia for major hip surgery. A clinical study of spinal and general anaesthesia in 244 patients. Reg Anaesth 1986;11(2): 83-8.

6. Simon MJ, Veering BT, Stienstra R, et al. The effects of age on neural blockade and haemodynamic changes after epidural anaesthesia with ropivacaine. Anesth Analg 2002;94(5):1325-30.

7. Meister GC, D'Angelo R, Owen M, et al. A comparison of epidural analgesia with $0.125 \%$ ropivacaine with fentanyl versus $0.125 \%$ bupivacaine with fentanyl during labour. Anaesth Analg 2000;90(3):632-7.

8. Wolff AP, Hasselstrom L, Kerkkamp HE, et al. Extradural ropivacaine and bupivacaine in hip surgery. British Journal of Anaesthesia 1995;74(4):458-60
9. Knudsen K, Suurkula BM, Blomberg S, et al. Central nervous and cardiovascular effects of IV infusions of ropivacaine, bupivacaine and placebo in volunteers. $\mathrm{Br} \mathrm{J}$ Anesthesia 1997;78(5):507-14.

10. Hansen TG, Llett KF, Lim SI, et al. Pharmacokinetic and clinical efficacy of long-term epidural ropivacaine infusion in children. $\mathrm{Br}$ Journal Anesthesia 2000;85(3):347-53.

11. Debon R, Chassard D, Duflo F, et al. Chronobiology of epidural ropivacaine: variation in duration of action related to the hour of administration. Anesthesiology 2002;96(3):542-5.

12. Morton CP, Bloomfield S, Magnusson A, et al. Ropivacaine $0.75 \%$ for extradural anaesthesia in elective caesarean section: an open clinical and pharmacokinetic study in mother and neonate. Br J Anaesth 1997;79(1):3-8.

13. Morrison LM, Emanuelsson BM, McClure $\mathrm{JH}$, et al. Efficacy and kinetics of extradural ropivacaine: comparison with bupivacaine. $\mathrm{Br} J$ Anesth 1994;72(2):164-9.

14. Peduto VA, Baroncini S, Montanini S, et al. A prospective, randomised, double-blind comparison of epidural levobupivacaine $0.5 \%$ with epidural ropivacaine $0.75 \%$ for lower limb procedures. European Journal Anaesthesiology 2003;20(12):979-83.

15. Brown DL, Carpenter RL, Thompson GE. Comparison of $0.5 \%$ ropivacaine and $0.5 \%$ bupivacaine for epidural anaesthesia in patients undergoing lower extremity surgery. Anaesthesiology 1990;72(4):633-6.

16. Liu S, Angel JM, Owens BD, et al. Effects of epidural bupivacaine after thoracotomy. Reg Anesth 1995;20(4):303-10.

17. Brockway MS, Bannister J, McClure JH, et al. Comparison of extradural ropivacaine and bupivacaine. Br J Anesth 1991;66(1):31-7. 